\title{
POLICY End-of-life care means exactly what it says: palliative care is about care at the end of life, not about ending life
}

\author{
Author: Ilora Finlay ${ }^{\mathrm{A}}$
}

It is fitting that, in its quincentennial year and half a century since Cicely Saunders founded the modern hospice movement, the Royal College of Physicians (RCP) should focus this month on palliative care. Britain has been ranked number one internationally in end-of-life care and our hospices have been commended by the Care Quality Commission. ${ }^{1,2}$ There are challenges, however, including improving access to specialist palliative care across geographical and disease boundaries. ${ }^{3}$ Resolving these and other practical issues will become increasingly important as more of us live with long-term conditions. But the science and the structures are there.

A fundamental principle of palliative care is (in the words of the World Health Organization), 'neither to hasten nor to postpone death'. Palliative care is about care at the end of life, not about ending life. Yet there are some who are urging that what they call 'assisted dying' should be seen as just another choice at the end of life and part of the palliative care toolkit. Along with the majority of doctors, I regard such ideas as highly dangerous.

Why do most doctors oppose being licensed to provide lethal drugs to their patients to assist their suicide? This is not, as some allege, about religion. While many people with religious beliefs oppose legalisation of assisted suicide, so do many with no such beliefs. This debate is about public safety, not about personal morality.

Opposition to assisted suicide is highest among those most closely involved in care of the dying. In the same year (2014) in which the RCP reaffirmed its opposition to a change in the law, a survey of its membership by the Association for Palliative Medicine revealed $82 \%$ opposition to a change in the law and only $4 \%$ of members willing to participate in such practices if ever they were to be legalised. ${ }^{4}$

Palliative medicine specialists see patients at their most vulnerable. A terminal prognosis can be a devastating blow. Even the strongest patients can be deeply vulnerable when brought face to face with their own mortality. They worry about how their illness will progress, what it will be like at the end, how their loved ones will cope - and indeed how they themselves will cope. Yet they are being told by 'assisted dying' campaigners that they have a choice between seeking assisted suicide and suffering 'a

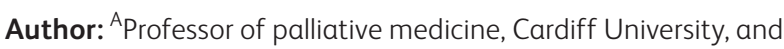
crossbench peer, House of Lords. painful and terrifying death, 5 Such ill-informed and irresponsible scaremongering has no place in end-of-life discussions.

The campaigners are indignant that 47 Britons went to Switzerland in 2016 to end their lives at the Dignitas assisted suicide facility. Yet they seem unconcerned that, if we had a physician-assisted suicide law here of the kind they commend, we would be looking at around 2,000 such deaths annually in England and Wales alone (based on applying officially published annual death rates from legal physician-assisted suicide in Oregon to numbers of registered deaths in each year in England and Wales). Relative to the total annual number of deaths, this may appear small, but it establishes new attitudes to death, dying, dependency and disability. Legalising an act does not just reproduce the status quo in legal form; it changes the dynamic completely. It sends the message that, if we are terminally ill, taking our own lives is an appropriate thing to consider - a choice to be made.

Campaigners may deny that they have ambitions for Dutch-style administered euthanasia, but I recall the late Lord Joffe's frank statement to a select committee some years ago that his Assisted Dying Bill was 'a first stage'. A Dutch-style 'assisted dying' law would have resulted in 21,000 such deaths in England and Wales in 2016 - one in 25 of all deaths. And the annual numbers in the Netherlands are rising relentlessly.

Public opinion polls, often sponsored by campaigning groups, may indicate support for 'assisted dying'. But how many of those questioned are aware of what is actually involved? This is not about upping dosages of morphine or stopping treatment. Symptom control as someone is dying involves titrating medication to achieve benefit while avoiding toxic side effects. When a life-prolonging treatment - such as ventilation - is stopped, the patient dies of the underlying condition, from which they would have died without the intervention - the patient dies of their disease (Fig 1a).

Assisted suicide and euthanasia (its big sister) are fundamentally different from this: they are designed deliberately to foreshorten a life that would have continued, possibly by months or years (Fig 1b). Assisted suicide consists of a massive barbiturate overdose (usually 9-10 g of secobarbital or pentobarbital). Euthanasia involves injecting a short-acting anaesthetic induction agent intravenously to render the patient unconscious, followed by pancuronium or similar to paralyse all movement, so the patient dies of asphyxia.

Clinical problems are in any case rarely the drivers of a desire for assisted suicide. Oregon's data show that inadequate pain control, or fear of it, comes low down on the list of reasons why people 


\section{(a) Withdrawing or withholding treatment}

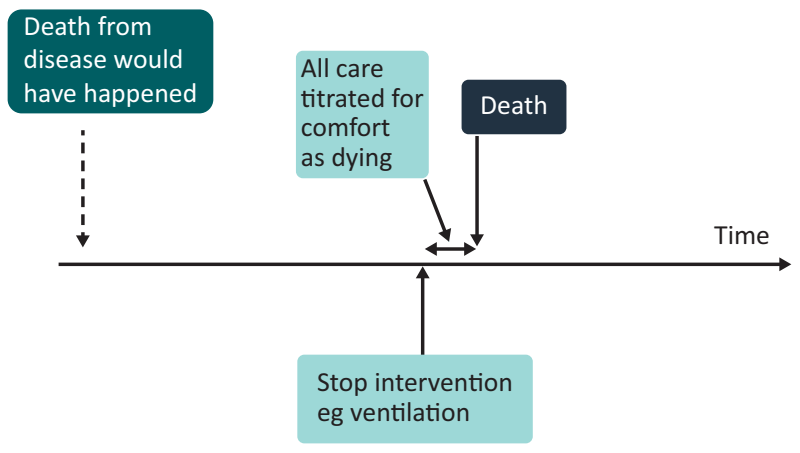

(b) Euthanasia/physician-assisted suicide

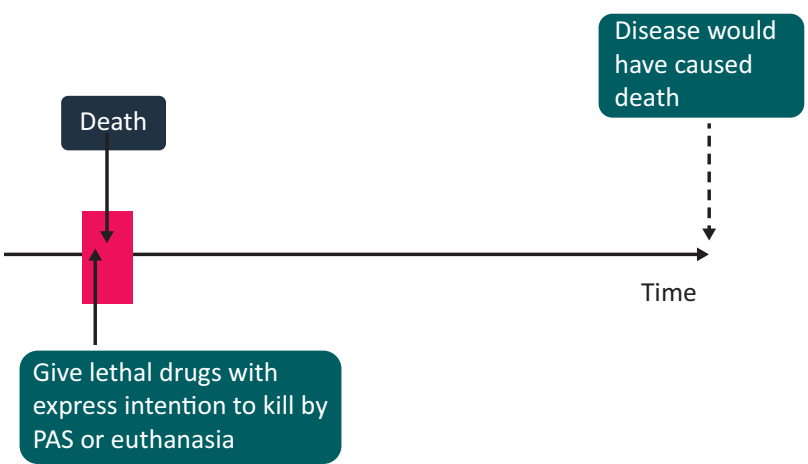

Fig 1. Schematic illustration of the relationship in time and intention between death and (a) withdrawal of life-prolonging treatment and (b) physician assisted suicide/euthanasia. PAS = physician-assisted suicide

seek assisted suicide. The main reasons are existential, such as not being able to enjoy life as before or wanting autonomy.

Campaigners for 'assisted dying' are irked by the opposition of doctors. They tell us that changing the law is a matter for society, not for the medical profession. They want medical professional bodies to stand back and adopt a position of neutrality. But what the campaigners are proposing (embedding assisted suicide in medicine) is difficult to reconcile with the fundamental principle of non-maleficence that underlies everything we do as doctors. A neutral position is not in reality neutral. It sends the message that the medical profession has no problem with assisting suicide.
That is very far from being the case. The effect of neutrality would be to muzzle the majority. Professional bodies cannot expect to have complete consensus on everything, but that should not stop them having policies that reflect the clear view of most of their members - and especially of those who would be most affected.

If this really is a matter for society, it should be placed fairly and squarely where societal decisions are taken - the High Court. The court has the skills and experience to examine complex issues from every angle and to reach balanced judgements.

Parliament has repeatedly rejected changing the law, most recently - and overwhelmingly - in 2015. But, if parliament were ever to be persuaded that 'assisted dying' should be made lawful, the role of doctors should be limited to providing advice to the court on the strictly medical aspects of any request, such as diagnosis, prognosis and treatment options. It should be for the court to seek advice on all the other aspects (family, social, psychological, financial), to weigh all the evidence and to reach comprehensive judgements.

Doctors have a key role to play in suicide prevention. They should not be put in the perverse position of preventing suicide for some but facilitating it for others. Embedding assisted suicide in clinical practice risks giving it a spurious aura of benevolence and of being a best-interests procedure. As most doctors recognise, it has no place there.

\section{References}

1 Economist Intelligence Unit. Quality Of Death Index 2015. Lien Foundation, 2015.

2 Care Quality Commission. The state of hospice services in England, 2014 to 2017. CQC, 2017

3 Lancaster H, Finlay IG, Downman M, Dumas J. The commissioning of specialist palliative care services in England. BMJ Support Palliat Care 2017. doi:10.1136/bmjspcare-2016-001119

4 Association for Palliative Medicine of Great Britain and Ireland. Survey on assisted suicide. 2015. Available online at www.apmonline.org [Accessed 16 December 2017].

5 Malthouse K. It's time to change the law to allow assisted dying. Conservative Home, 2016. Available online at www.conservativehome.com/platform/2017/12/kit-malthouse-its-time-to-change-thelaw-to-allow-assisted-dying.html [Accessed 6 December 2017].

Address for correspondence: Professor Baroness Ilora Finlay of Llandaff, House of Lords, London, SW1A OPW.

Email: finlayi@parliament.uk 